\title{
Barriers and Facilitators for Implementing Mental Health Services into the Ethiopian Health Extension Program: A Qualitative Study
}

This article was published in the following Dove Press journal: Risk Management and Healthcare Policy

\author{
Kiddus Yitbarek (D) \\ Zewdie Birhanu ${ }^{2}$ \\ Gudina Terefe Tucho $\mathbb{D}^{3}$ \\ Susan Anand ${ }^{4}$ \\ Liyew Agenagnew (D) $^{5}$ \\ Gutema Ahmed Snr $\mathbb{D}^{5}$ \\ Masrie Getnet ${ }^{6}$ \\ Yonas Tesfaye $\mathbb{D}^{5}$ \\ 'Departemnt of Health Policy and \\ Management, Faculty of Public Health, \\ Jimma University, Jimma, Ethiopia; \\ ${ }^{2}$ Department of Health Behaviors and \\ Society, Faculty of Public Health, Jimma \\ University, Jimma, Ethiopia; ${ }^{3}$ Department \\ of Environmental Health and Technology, \\ Faculty of Public Health, Jimma \\ University, Jimma, Ethiopia; ${ }^{4}$ Department \\ of Nursing, Faculty Health Sciences, \\ Jimma University, Jimma, Ethiopia; \\ ${ }^{5}$ Department of Psychiatry, Faculty of \\ Medical Sciences, Jimma University, \\ Jimma, Ethiopia; ${ }^{6}$ Department of \\ Epidemiology, Faculty of Public Health, \\ Jimma University, Jimma, Ethiopia
}

\begin{abstract}
Purpose: The Ethiopian Ministry of Health has integrated mental health services into the community health service, but it has not yet been implemented. Therefore, this study aimed to explore the barriers and facilitators of mental health service implementation in the Ethiopian community health program.
\end{abstract}

Methods: A qualitative case study was conducted in the Ethiopian primary health care system in 2019. We have conducted about eight key informant interviews with policymakers, service managers, and service providers. The interviews were tape-recorded, transcribed, translated, and analyzed manually using the World Health Organization building blocks framework.

Results: The Health Ministry of Ethiopia has recently included mental health services into the health extension package but not yet implemented as part of integrated services. The identified barriers were low political commitment, shortage of resources, non-functional referral system, lack of interest from private health service organizations, attitudinal problems from both the society and service providers, and lack of consistent reporting system of the mental health problems. However, the well-designed primary health care system, trained health extension workers, changing political commitment and attitude of the community could facilitate the mental health service implementation.

Conclusion: A series of activities are expected, especially from the healthcare system managers to implement, follow, and evaluate mental health services implementation at the health extension programs.

Keywords: mental health services, health extension workers, primary health care, Ethiopia

\section{Introduction}

We live in a complex, fast-moving, and interconnected world in which the importance of physical, mental, and social wellbeing has not been well emphasized. In this interwoven situation of life, we could understand that mental health plays a vital role in the well-being of individuals, the community, countries, and the entire world. ${ }^{1,2}$ The world health organization (WHO) has defined mental health as "a state of well-being enabling individuals to realize their abilities, cope with the normal stresses of life, work productively and fruitfully, and make a contribution to their communities. ${ }^{3}$ Accordingly, more than 450 million people worldwide suffer from mental and behavioral disorders, and about 1 million people commit suicide every year due to mental disorders. ${ }^{3}$ The related economic loss is also huge, globally each year, it costs more than 1 trillion US dollars in lost productivity
Correspondence: Yonas Tesfaye

Po Box: 378

Tel +251910107507

Email yonastesfaye7I@yahoo.com
Risk Management and Healthcare Policy 2021:14 I|99-1210 
time. ${ }^{4,5}$ Despite being a global health issue with economic repercussions, the provision of services for mental health and mental disorders in the healthcare sector of many countries has been emphasized. ${ }^{6}$

The situation is very high in low-income countries. According to the World Bank Group and WHO, low and middle-income countries contribute about $80 \%$ of people who have experienced a mental disorder in their lifetime. ${ }^{7,8}$ Nevertheless, these countries did not give much attention to major health issues. ${ }^{9,10}$ This imposes a significant burden on the economy and well-being of the society in these countries. The productivity loss due to mental disorders, treatment costs to mentally ill people, and the exposure of these people to other co-morbidities forced governments to depend on foreign aids..$^{711-13}$ Therefore, the provision of cost-effective and efficient measures to combat this disabling problem has become exigent for low-income countries. This makes a call for using the existing primary health care (PHC) structure to address the needs of the vast majority of the population. ${ }^{14}$

In Ethiopia's population of around 100 million, neuropsychiatric disorders are estimated to account for 5.8\% of the disease burden. ${ }^{15,16}$ In Ethiopia, depression contributes to about $6.5 \%$ of the burden of diseases. ${ }^{17}$ In a predominantly rural area, mental disorders were estimated to be responsible for $11 \%$ of the total disease burden, schizophrenia, and depression among the top ten most burdensome conditions. ${ }^{18,19}$

Untreated mental disorders lead to disability, create a substantial personal burden for affected individuals and their families, low quality of life, human rights abuses, stigma and discrimination, poverty, decrease productivity, suffering, poor physical health, and premature mortality. ${ }^{20-22}$ Due to the burden of mental disorders, the available treatment gap, and high co-occurrence of physical and mental disorders, the integration of mental health in the primary healthcare service package is essential to increase access to the services, reduce stigma, and provide affordable and low-cost health services. ${ }^{23}$ The integration is in all health care services and most importantly in PHC, (Specialist mental health workers are scarce in LMIC settings and cannot, in isolation, provide the solution to the MNS disorder treatment gap, ${ }^{24}$ In Ethiopia, there is about one psychiatrist per two million people $\mathrm{e}^{25}$ and only an estimated 0.68 mental health professionals per 100,000 people, ${ }^{26}$ concentrated mainly in urban areas and hospital settings which are not accessible to the majority of the population. Integrating mental health care into primary health care (PHC), through a model of task sharing with mental health specialists, is therefore advocated as the best approach to narrow the treatment gap for MNS disorders. ${ }^{27}$ Providing mental health care in the PHC setting has other potential benefits, including more holistic care and better physical health outcomes, reduced stigma, and more locally available care with a resultant decrease in the economic burden of care and a greater chance of maintaining contact with community and family support systems. $^{28}$

The Ethiopia Ministry of Health has implemented the second-generation health extension program in 2019 across the nation. ${ }^{29}$ The second-generation health extension program would be implemented primarily through enhancing health clinic services and the capacity of health professionals. ${ }^{29}$ The implementation of the PHC approach relies on health workers, including community health workers (CHWs). Community health worker embraces a variety of community health aides. CHW are members of the community who are selected by the community members or organizations to provide basic health and medical care to their community. As such, CHWs represent an important health resource with a potential to provide a reasonable level of health care. ${ }^{30}$

Therefore, the provision of cost-effective and efficient measures to combat this problem has become exigent for low-income countries. This makes a call for using the existing primary health care (PHC) structure to address the needs of the vast majority of the population. ${ }^{14}$

Although it has not been implemented in most countries, promoting mental health had been outlined as one of the essential elements of primary healthcare during the Alma Ata declaration of $1978 .{ }^{31,32}$ However, many countries of the world did not immediately integrate mental health services in the primary healthcare system. ${ }^{33,34}$ Ethiopia has lately integrated mental health services into its primary healthcare system. $^{35}$ In Ethiopia, primary healthcare forms the first tier of the country's three-tiered healthcare services structure. The service wing of primary health care includes primary hospitals, primary health centers, and satellite health posts. Health posts are the first contact units for the patients where the service is provided with an average of two health extension workers (HEWs). They mostly provide preventive and promotive healthcare services through house-to-house visits and at the health post. Currently, the country has over 42000 HEWs working at health posts. These frontline health workers are 
responsible for providing eighteen health services packages primarily designed to prevent diseases and promote better health services. The whole process of primary healthcare services is overseen by a district health office. ${ }^{36,37}$

Health extension programs (HEP) helped the country to achieve various health indicators. This success motivated the government to update the existing HEP with the inclusion of mental health as the $18^{\text {th }}$ health services package. ${ }^{29}$ However, it has not been practically implemented in health posts and primary care services, ${ }^{29}$ although about $75 \%$ of the HEWs have taken in-service training on the newly added packages, including mental health services, in 2018-2019. Based on these, we have questioned why mental health services were not still implemented in the country's health extension program. Therefore, the objective of this study was to identify barriers and facilitators of implementing mental health services in the Ethiopian health extension program.

\section{Methods}

\section{Study Setting Design}

Overall, we did a case study to explore the Ethiopian primary health system to see the possibilities of implementing mental health services in health extension programs. The entire chain of health extension programs from the central ministry of health-to-health extension workers working in the community was taken as a case. Ethiopia is the largest landlocked country located in the horn of Africa. The country shares border with Eritrea from the North, Djibouti, and Somalia from the East, Sudan, South Sudan from the West, and Kenya from the Southern direction. The second populous country in Africa has a 107.53 million population with an equivalent proportion of males and females. The country's capital, Addis Ababa, is the home for the African Union's headquarter and the second diplomatic city in the world.

Ethiopia's health service delivery is structured into a three-tier system: primary, secondary and tertiary levels of care. The HEP is positioned, implemented and managed under the umbrella of the primary health care unit (PHCU). Two HEWs are assigned to one health post to serve a population ranging from 3000 to 5000 in a village (kebele). Five health posts and a health center work in collaboration and form the PHCU that serves 25,000 people. The health center serves as a referral center. The health post is under the supervision of the district health office and the kebele administration and receives technical support from the nearby health center. ${ }^{30}$

The health system also has an administrative and policy-making wing, service delivery wing, and community wing. The health extension program is a community-based health service delivery at the primary health care level, mainly administered by health extension workers trained for the purpose. The policy-making and administration of this program start from the national ministry of health up to primary health care units (PHCU). We have conducted a qualitative study from 12 August to 25 September 2019.

\section{Study Participants and Data Collection}

We have conducted a total of eight key informant interviews with purposively selected key informants. Respondents working units and knowledge of the subject matter were considered when selecting them for the study. We have considered maximum variability when selecting HEWs for the survey. We also considered the main constituency when selecting key informants for the interview. The key informants comprise policymakers, decisionmakers, health system managers, and health service practitioners (HEWs).

We have followed the Ethiopian HEP and mental health services administration system during the selection of key informants and data collection. Two key informants were interviewed from each ministry of health noncommunicable diseases prevention and control directorate, PHC and HEP directorate, respectively. Following the chain, next, we have gone to the Oromia regional health bureau. Similarly, we have information from two key informants from the non-communicable disease prevention and control division and the PHC division's prevention and control. Keeping the chain, we have directly gone to the service managing level. We have taken one district from the Jimma zone, which is located in Oromia regional state. Two key informants (non-communicable diseases coordinator and HEWs coordinator) were interviewed in one district's health office. Eventually, two additional interviews of HEWs in the Health Posts located in Seka Chekorsa district of Jimma zone were conducted.

We have used a pre-designed unstructured interview guide to lead the interview [Supplementary file I]. Each of the interviews was conducted by two interviewers. The data collectors were mental health professionals with a master's degree working in the health system. All the interviewers were undertaken in the local language, which both the interviewers and interviewees understood well. 
All the interviews were tape-recorded and vital points jotted down in a notebook.

\section{Data Processing and Analysis}

All the tape-recorded data were transcribed verbatim into written transcripts and translated into the English language. We then managed and analyzed the data manually. Two of the investigator's KY and YT, read the transcripts repeatedly and assigned codes manually using excel spreadsheet tables [Supplementary file II]. Rigorous discussion among the investigators was done on the initial codes to reach on consensus. Codes were then grouped into sub-themes. The subthemes were pre-determined based on the WHO building blocks framework. The framework involves six building blocks, including medical products and technology, health systems leadership and governance; information and research; service delivery; finance; and human resources. From these sub-themes, based on the emerged information from the qualitative data and discussion about the relevance of themes in the HEP, we have presented the key findings under four themes, including health systems leadership and governance, service delivery, human resource, and finance. Eventually, both the investigators double-checked the themes after analysis with the transcripts and the statements quoted in each sub-theme.

\section{Ethics Approval and Consent to Participate}

The proposal of the study was reviewed and approved by the Institutional Review Board (IRB) of Jimma University institute of health. Before data collection, letters of support were taken from the Health Ministry of Ethiopia, Oromia Health Bureau, and Jimma zone health department to Seka Chekorsa Woreda health office. Additionally, the interviewees were briefed on the study objectives and methodology and were assured of the anonymity of their participation. Moreover, oral informed consent was obtained from the study participants. This study complied Declaration of Helsinki, and the participants provided informed consent to have anonymized responses published.

\section{Results}

\section{Description of Study Participants}

We did a qualitative study on the Ethiopian primary health care system starting from the top-level policymakers to the bottom-level health care managers and health extension workers (HEWs). A total of 8 respondents participated in the study. The first two were policymakers at the national level from the non-communicable disease directorate and PHC and HEP directorate. Two of them were decisionmakers at the regional level and the other two were from service management bodies, district health offices. We finally took information from two health extension workers (Table 1).

\section{Mental Health Problem in Ethiopia}

Mental health problems are not well studied in Ethiopia. But recent findings indicate that there is a high burden of mental health problems in the country. According to an expert from the $\mathrm{MOH}$, non-communicable diseases directorate, mental health problems are increasing fast in the country recently. Referring to a meta-analysis conducted in 2018 he said, the prevalence of mental health problems in the country is $28 \%$. Another interviewee from PHC and HEP directorate supports this idea. He said, "the burden of mental health problem is very high these days in our country [Ethiopia]." This idea was also supported by the interviewee from ORHB's non-communicable diseases prevention and control division.

Respondents from the Oromia regional state health bureau also mentioned some possible reasons for the increasing burden of mental health problems. The economic strain of the people in the country contributed to the burden of the problems. According to the respondents, the current high unemployment rate and extreme poverty are major reasons for the recent mental health problems. Furthermore, they stressed that drugs in many areas of the country could be the primary reason. There are local drinks like "Areke," "Tela," "Tej," and mostly used local stimulant leaf called Khat [amphetamine like stimulant drug commonly abused in the East, North Africa, and Middle East regions] are common in most parts of the

Table I Description of Qualitative Study Participants, Ethiopia, 2019

\begin{tabular}{|l|l|l|}
\hline $\begin{array}{l}\text { The Main Constituency } \\
\text { Represented }\end{array}$ & $\begin{array}{l}\text { Level of the Health } \\
\text { System }\end{array}$ & Number \\
\hline Policy-maker & National & 2 \\
Decision-maker & Regional & 2 \\
Health care manager & District/Local & 2 \\
Healthcare worker & Service providers & 2 \\
\hline
\end{tabular}

Notes: Supplementary file I-Key informants guide. Supplementary file II-Codes. 
country. Especially the use of Khat is increasing fast. Regarding this, one respondent from $\mathrm{MOH}$ said,

... for example, Khat [a local stimulant leaf] use was more prevalent in the eastern part of Ethiopia than the north part, but nowadays the use is spreading fast to the northern parts of the country.

The other major reason for the recent high prevalence of mental health problem magnitude is the recurrent internal displacements in the country. Political disputes were here and there, especially in Ethiopia's largest regional states, like Oromia, Somali, Amhara, and South Nations, Nationalities and Peoples (SNNP) regions. The dispute ended with a significant number of deaths, property loss, and displacement of inhabitants from their original living area. They have been forced to live in temporary camps. The displaced people have experienced terrible situations during the conflicts and the camps. For instance, a mental health focal person from ORHB reported that:

There is an increase in mental illness in recent times because of the displacement of a significant number population in the region [Oromia region]. The burden is high among those displaced people living in settlement camps. Many of them lost their families, and some saw their relatives killed in front of themselves. They were also under stressful conditions. Therefore, post-traumatic stress disorder, depression, anxiety, and psychotic feature are prevalent among this population. The mental health cases were more seen in camps around Sululta and Bishan Guracha [Two of the centers for displaced people].

The mental health focal person in the MOH has seen the burden dividing into the urban-rural residence. " ... if you ask me the difference in the rural and urban areas, I can say, it [mental health problem] is more prevalent in urban areas," he said. This difference could be factors like displacement, unemployment, psychoactive substance use are more common in urban areas of the country.

In an interview with these HEWs, we recognized that they had observed some people with signs and symptoms of mental health problems during their house-to-house visit in their catchment population. For instance, one 32 years old HEW said:

... in my kebele [the smallest administrative division in Ethiopia where HEW serve], I have seen some mentally ill patients [according to her definition] who insult everybody, throwing a stone, being physically aggressive. I also observed a boy who got into conflict and disagreement with his family. Another guy also was highly suspicious of his mother, and he kicked out all the family members from their house and started living alone. These can be examples of the mental health problem in my working area.

\section{Mental Health Services in Ethiopia}

The Ethiopian health service delivery system has three tiers. At the tertiary level, highly specialized medical services being given on a referral basis. At the secondary level still, services are provided based on a referral basis. Still, the specialty and the number of catchment populations are lower than the tertiary level care. On the other hand, at the primary level, mostly preventive, promotive, and essential curative services are being given. This primary health care is currently administered at primary hospitals, health centers, and satellite health posts.

Regarding mental health services, the actual practice in Ethiopia tells us that the services are administered only in tertiary level hospitals. There is only one specialty hospital for mental health service situated in the capital of the country, Addis Ababa. There is a framework to deliver the services at general hospitals [secondary level] and primary level hospitals. However, because of different reasons, the activity remains in some of the health facilities. The vast majority of the population living in a rural setting who need care were not benefited. The mental health focal person in the ministry of health mention the reasons for this limited health service access. The first fundamental issue is the shortage of trained professionals. According to him:

... the service [mental health service] is not well developed; imagine we do have only 60 psychiatrists in the country. There are also mental health professionals at bachelors, master's degree level. However, all these professionals are not actively working in psychiatry clinics. Some, especially those at masters level, remain in office work in one health administrative organ.

The information we obtained from the Oromia regional health bureau mental health focal person supports this argument. There is a high turnover of mental health professionals because of transfer and promotion. The promotion policy in the region supports the transfer of health professionals from health facilities to administrative offices. Therefore, the regional state has lost many mental health professionals from their actual clinic area.

The expert from the HEP directorate of the ministry of health sees the reason from another angle. According to 
him, the source of the problem is the absence of clear policy documents at the national level. For instance, "the mental health strategy that was prepared and completed in 2015 hasn't been endorser until now [in 2019]," he said. The strategy document was prepared based on international best practices and the world health organization's (WHO) recommendation for low and middle-income countries. The strategy indicates mental health services have to be given up to the lower level of care.

Acceptance of the service from the users' side and the community angle is generally still low. In most parts of Ethiopia, mental health problems are considered a punishment from God or some kind of evil spirit possession. They, therefore, prefer traditional healers and religious organizations avoiding orthodox health services.

According to an expert from the Oromia regional health bureau's health extension program directorate, the best way to deal with this negative attitude is by changing community behavior. The regional health bureau has implemented and achieved many health indicators is through community health service activity by health extension workers. The community's health-seeking behavior about maternal and child health service and infectious diseases control and treatment were significantly changed with the health extension program. The expert said: "The best way is to form a link between HEW to primary hospitals and specialized hospitals." Health extension workers can mainly participate in identifying and linking those suspected cases to mental health clinics at health facilities.

\section{Integrating Mental Health Services into the Health Extension Program}

The recently updated health extension program consists of eighteen health service packages. Among these packages, mental health service is one. Based on these packages, the ministry of health has developed a training manual to give refresher training to existing HEWs and full package training to newly recruited candidate HEWs. Their primary role in mental health service is to provide behavior change education, identify suspected mental health cases with vital signs and symptoms, link to health service keeping their referral chain, and follow up treatment adherence. The integration of mental health services into health extension packages was first started in the urban health extension program. It was then expanded to the rural health extension program. Currently, mental health services are integrated into both the urban and rural health extension packages.

\section{Barriers and Facilitators of Mental Health Services Implementation in Ethiopia}

As it has been revealed in various health indicators in Ethiopia, the implementation of HEP has significantly changed the health status of the community. Since the focus of HEP is on prevention and promotion, the burden in health facilities was minimized. The health system saved a substantial amount of resources that could have been used for curative services. Similar benefits are expected while implementing preventive and promotive mental health services with the HEP in Ethiopia. That is why the government has included mental health services in health extension packages and trained HEWs with the necessary modules. However, as the information we obtained, the program packages were not implemented so far.

\section{Facilitators to Implement Mental Health Services with HEP Health System Management and Governance}

The Ethiopian health care tier system is a well-designed primary health care structure. There is a service management system called the primary health care unit (PHCU) under the primary health care structure. In this unit, there is an average of five health posts with a referral health center. The administrative organ of these units is the district health office. The health center oversees all the services and the activities of health posts. Currently, in this system, there is also a primary referral hospital. Cases that could not be managed at the health center level will be referred to primary hospitals. The district health office supervises the overall service at the PHCU. Our key informants from the ministry of health of Ethiopia and Oromia regional health bureau consider this established system and management an excellent opportunity to implement mental health services.

There are also policy documents and strategies that help the implementation of the services. The currently available health extension program guideline includes mental health as one of the main components. The study participant from non-communicable diseases prevention and control directorate:

We are working collaboratively with PHC and HEP directorate, while they were preparing the guidelines [HEP 
guideline]. We also develop plans together regarding the mental health services in the PHC system.

Despite its delay in implementation, there is a mental health strategy document in the ministry of health. This document has given due emphasis to managing mental health problems at the primary health care level.

\section{Mental Health Service Delivery}

Government officials and the ministry of health are now giving concern to mental health and mental health services. Previously there was no even a focal person dealing with mental health in the ministry of Health. However, recently a case team dedicated to mental health was established under the non-communicable disease directorate. The ministry is fulfilling the case team with human resources. The same is true in Oromia regional state health bureau. The Oromia regional health bureau respondent stated: " ... the government now is committed to expanding the services ..."

\section{Human Resources}

In Ethiopia, there are about 42000 HEWs actively working in health posts and community outreach. It has been two HEWs averagely per health post. Meanwhile, currently, the ministry started increasing the number of HEWs to four per health post. The level of training given to HEWs was up to level three. However, currently, the training manual and packages were updated, and they get training up to level four. HEWs get training on preventive, promotive, and basic management of mental health problems at this level. "There are $20000 \mathrm{HEWs}$ trained up to level four in the country" [Ministry of health, PHC and HEP directorate].

Contrary to this, a HEW interviewed in one of the Jimma zone districts responded that she and her colleague have not got trained on mental health and mental health services. We then confirmed this information from a respondent working in the district health office. He said that he has no information regarding mental health training given to HEWs so far.

\section{Barriers to Implementing Mental Health Services with HEP Health System Management and Governance}

The focus of the health systems managing body in Ethiopia is mostly on donor-focused communicable health problems and maternal and child health issues. The managing body has given priority to similar health issues in the policy and strategy documents. The mental health focal person in the ministry has a great concern about this. He said:

.... look at the MOH mission and vision; its entire focus is on infectious diseases prevention, promotion, and curative aspects, but they have ignored the rehabilitative aspect.

This concern does not remain a problem by itself. It then translated to the shortage in the availability of medical supplies, lower budget, and absence of incentive packages and staff retention strategies for mental health professionals.

From the responses of one of the respondents in the ministry, we could catch that mental health services are not integrated well with the PHC system starting from the ministry of health. "We are not the one planning mental health services." a respondent said from PHC and HEP directorate. They perhaps support the planning and policy department during issues related to integrating mental health into HEP.

The private health care delivery system is also the other center of focus. According to the key informants in the ministry of health, engagement of private institutions in the service [mental health service] is very much minimal.

There are only some two or three facilities giving specialty mental health services in Addis Ababa, the capital of Ethiopia. In other big towns, there are no such dedicated private health facilities for mental health. $[\mathrm{MCH}$ and HEP expert]

\section{Human Resources}

The major difficulty that all the respondents raised was the shortage of resources for mental health services. The referral system does not look functional for mental health services. Despite the availability of HEWs trained with mental health packages, there are no mental health professionals at the referral health center and primary hospital level. Even though HEWs are trained in identifying and linking suspected people with mental health problems, the referral health centers and primary hospitals do not give services to the patients. There is a shortfall of human resources trained in mental health. According to informants from the ministry, the total number of psychiatrists in the country does not exceed 60. Similarly, the health system is in short of psychiatry nurses and other mental health professionals. Therefore, even if there is a demand 
for mental health services at each health system level, the ministry could not fill the gap.

Therefore "why the government does not train the student in this field of study and fill the shortage of professionals?" could be a reasonable question. As has been described above, the respondents agreed that, despite the prevailing mental health problems in the country, the focus of health system administrators and policy documents is on other issues like infectious diseases and maternity care. "... this is the main problem in the country ..." a respondent from the ministry said. Therefore, most education programs and many students join education programs, directed to what the government outlined priority. These are the main problems occurring in most government health and medical schools.

It is not only from the government administration side; students who join medical and health schools negatively perceive mental health courses. Regarding this, the PHC and HEP focal person in the ministry said that

... up on my experience many people do not like the profession [mental health]. For instance, if you see physicians, most of them do not prefer to specialize in psychiatry.

When a respondent from Oromia regional health bureau justifies this issue, he said: "there is a widespread poor attitude that a person who treats mental health problems would be a mentally ill afterward." The cumulative effect eventually left the country in short of mental health professionals.

\section{Finance}

The other primary concern is financial constraints. Ethiopia is among the countries that have the lowest per capita health expenditure in the world. Moreover, more than two-thirds of the country's health care finance is dependent on external funds and out-of-pocket payments from users. In this country, the amount of budget and finance spent on mental health services is meager. Based on this, we have traced back to why mental health has a low policy and political concern. The mental health focal person in the ministry disclosed improvements in the allocated amount of budget for the service in recent years. "Comparing to the past, currently more budgets are being allocated for mental health services," he said.

The other primary source of finance in Ethiopian health care is an international organization and bilateral aids. In this regard also, mental health services do not benefit.
Most external aids are mainly spent on services like maternity care and infectious diseases control purposes. "For example," says the PHC and HEP focal person in the ministry,

... most of the other programs in the ministry are supported by international development organizations. As far as I know, mental health has no support, except little amount of monitory and technical support from WHO.

Therefore, it would be challenging to address the mental health need in the country with the sum of the available amount of finance. Both Respondents from the Oromia regional health bureau and non-communicable diseases focal person in the Jimma zone agreed with this issue. They frequently looked for additional funds from external organizations, but they left with nothing. “ ... we have requested [fund for mental health service], but I think they [external aid organizations] are not volunteer to support mental health services ..." said the mental health focal person in Oromia regional health bureau. There are no external collaborators at the regional and district levels.

\section{Service Delivery}

For long HEWs have been serving in the Ethiopian health care system as community health workers. There is an average of about two HEWs working in a health post. A single health post is supposed to give service averagely to 5000 population. That means two HEWs provide the services to more than 1000 households living in a kebele. They serve the people both based in a health post and house-to-house visit. According to respondents in the ministry, they have a significant impact on improving the health status of the community in the country. However, their pay scale is the lowest in the public health system career structure. Therefore, there is a fear that HEWs may lose their commitment when a new service package is integrated and became add up to the existing one.

We are forced to cover a long-distance foot walk to address all the households in a kebele. We are loaded with the existing health service packages. All the assigned HEWs do not always available onboard for assignments. Some of them may be on maternity leave, and some may absent from their work. On top of this, I have not got any mental health training so far. Therefore, how can I supposed to do additional activities? [28 years old level 3 HEW]

It could be challenging to administer mental health services in the existing HEP arrangement and career level. 
We have also got a similar response from the ministry of health PHC and HEP directorate.

There are also some more challenges from the community side to use the available health services. In most parts of the country, people, especially those living in rural areas, consider mental health problems as some evil spirits and look for some traditional healers or religious organizations. The problem is grave in a country with more than $85 \%$ of rural residents. Some community members are not willing to accept advice from a health professional and HEWs. A HEW respondent in this regard said, “... some of them [community members] are not willing to take our advice ..." Respondents from Oromia regional health bureau have strengthened this view. According to their thought, there is an adverse perception of the causes of mental health problems and a negative attitude regarding mental health services. This would be a challenge when implementing mental health services with HEP.

\section{Information Systems}

The Ethiopian health system monitoring and evaluation generally guided by a system called the health management information system (HMIS). It is an electronic and manual platform that enables the smooth transfer of information from and/or to the bottom level of health service delivery to the ministry of health. The system has predefined health-related indicators. Therefore, the reporting of health events directly adheres to these pre-defined indicators. According to the information we have received from the Ministry of health and Oromia regional health bureau, there is no indicator of mental health in the system. The mental health focal person has given stress to this point. He said, “ . . the complaint before was this one. The service [mental health] had no indicator in HIMIS" However, the HMIS system currently is under the process of update. The newly designed system, the district health information system (DHIS2), consists of mental health indicators. "Starting from the current fiscal year, mental health indicators will be included in DHIS 2," he said.

\section{Discussion}

The origin of community health workers' activity trace back to the Chinese barefoot doctor's approach to service. Since then, community health service has been practiced in many countries of the world and found useful. Ethiopia has started implementing a structured community health workers approach since 2003 to support primary health care in the preventive and promotive aspects. The service used to have sixteen health service packages before being updated recently. Many countries achieved health-related goals with this approach. Low and middle-income countries like Zambia, Uganda, and Bangladesh integrated their mental health services with a community health approach and shown massive improvement in mental health and service use. ${ }^{34,38,39}$ Preventive, promotive, and rehabilitative mental health services were integrated into the Ethiopian HEP in 2015. ${ }^{40,41}$ However, the service has not been fully implemented yet in the country.

The findings in this study indicate, there is a high burden of mental health problems in Ethiopia. Quantitative figures also show that mental illnesses, especially depression and anxiety, are most common in various countries. ${ }^{42}$ Relatively the same happens in other African countries. ${ }^{43}$ Currently, these cases are frequently happening because of some predisposing factors. Substance use is increasing in many parts of the country, particularly among young and adolescent age groups at secondary schools and colleges vulnerable to this situation. ${ }^{44,45}$ The internal displacement could also be one major reason for the current peak situation. Currently, in Ethiopia, there are more than three million internally displaced people because of political disputes. Some documents indicated Ethiopia recorded the third-largest internal displacement in the world. ${ }^{46}$ Therefore, post-traumatic syndromes, depression, and anxiety disorders could be expected because of the conflicts and their current difficult living conditions.

The people, in most cases, use traditional and religious ways of treatment to treat mental health problems. Mostly they associate the disease with an evil spirit possession or a punishment from God against their sins. More severely, some families keep a member with mental illness in their house without any treatment. It is the case in many African countries too. For instance, a study conducted in South Africa indicated that mentally ill people live in dangerous situations. ${ }^{47}$ They mostly experience stigma, they do not get the necessary treatment, and they even do not get the required treatments for other co-morbidities. ${ }^{47,48}$ These problems create poor achievements in mental health preventive, promotive, curative, and rehabilitative services in Ethiopia and other countries with a similar situation. This is the reason that triggers the health system to avail health service as nearest as possible to the population. Various literature suggests giving service at the PHC level is a better initiative to enhance society's health at the grassroots level, especially in low-income countries. ${ }^{49-51}$ On top of this, others also suggest continuing education and 
appropriate supervision for primary care workers would lead to success. ${ }^{52}$

Although integrating mental health issues in the primary health care delivery system is the right approach, its practicality is difficult in a resource-limited country. For instance, when we see the Ethiopian situation, a wellstructured primary health care system and strategic documents support the integration of mental health service into the system. ${ }^{53}$ However, the practice has not been started yet. Health systems and programs people in the Ethiopian healthcare system list lots of reasons for this occurrence. Even though mental illness is a big problem in the country, leaders in the health care system and most policy documents have not made this issue a priority problem. Failures of various health service approaches give a lesson that ${ }^{54,55}$ if there is no political commitment in the health care system, it would be merely the result of low effort.

The resource is at the heart of the health care system. In resource-limited countries, it is a headache to allocate the existing few resources into various health services. For instance, in Ethiopia, a country with more than 110 million population, there are only about 60 psychiatrists and not more than 500 other mental health professionals mostly accumulated in the country's capital. ${ }^{53}$ Most primary health care facilities like primary hospitals and health centers have no mental health professionals. ${ }^{53,56}$ A consistent finding was reported from the study done in Uganda. $^{57}$ Likewise, budget is the other big problem implementing mental health services up to the household level. ${ }^{58}$ It would also be a big problem in countries dependent on external funding. More than one-third of Ethiopia's health care finance is covered by the external world. ${ }^{59}$ A similar report was documented from the study done in Uganda; some of the health centers had donorfunded projects with a set plan and necessary resources to achieve the aims. The impacts of foreign aid were not clear to some participants, causing them to think that mental health care is neglected and therefore not necessary. ${ }^{57}$ Thus, even decision-makers have to stick with the funders' interest that they do not have full autonomy to prioritize health problems.

On the other hand, some attitudinal and behavioral issues in the community and health care providers affect the implementation of mental health services in the community health service. In a country with about $85 \%$ rural residents and mostly uneducated, ${ }^{60}$ obtaining mental health services is not as easy. According to our findings, uneducated people, even educated and health care workers, have a negative attitude toward mentally ill people and the service itself. As part of the community, some HEWs have a poor attitude regarding mental illness and mentally ill people. We have also identified other barriers like; inadequate knowledge of community members, lack of indicators in the reporting system, lack of need from students to join mental health professions, etc. A systematic review has also revealed that the same barriers happen in other low-income settings. ${ }^{58}$

On the other hand, our study has identified some major facilitators that help to implement mental health services at the community level. Implementing mental health services in the PHC system does not need a considerable establishment cost in Ethiopia. ${ }^{35}$ Not only the ministry of a health-led health system but in the country, there is also a community arrangement led by voluntary community health workers that supports the health care system. ${ }^{61}$ Using these systems as a strategy helps to implement mental health services at a minimal cost. More than $42000 \mathrm{HEWs}$ working in various parts of the country are mostly trained with basic mental health services. Experience in many countries indicated that implementing mental health services in the community health workers' system has resulted in improvements in many mental health indicators. ${ }^{62,63}$

A study done in Uganda revealed respondents reported they had not received in-service training in the mental health area. The health care providers felt that mental health was not as crucial as other diseases where a lot of attention and resources were directed. Some health centers had donorfunded project $\mathrm{s}$ with a set plan and necessary resources to achieve the aims. This was not clear to some of the participants thus causing them to think that mental health care is neglected and, therefore, considered unnecessary. There were no regulatory measures at the health facilities to encourage them to screen for mental health problems. ${ }^{57}$

\section{Conclusion}

Overall, we have found that mental health problems are increasing at an alarming rate and should be a major concern in Ethiopia. Yet, the currently functioning mental health services is not capable enough to respond to the current need. Preventive and promotive mental health services were integrated into the country's health extension program, but the services were not provided yet in the system.

We have identified a low level of concern among health system leaders and policy documents, low-level of publicprivate partnership, inadequate and donor-dependent budget, 
low acceptability of the services from both the community and HEWs, low commitment of HEWs, absence of mental health indicators in the Ethiopian health information system were identified as barriers to inadequate mental health services. On the other hand, some factors could facilitate mental health services within the health extension program. Integrating the mental health service in the health extension program as one of the primary health components, availability of the policy documents, and the availability of well-trained HEW at the grassroot level could be considered facilitating factors.

In general, implementing mental health promotive and preventive health services at the grass-roots level through HEWs would have paramount importance for mitigating and controlling the devastating effect of mental health.

\section{Acknowledgments}

We would like to acknowledge the Ethiopian Ministry of Health and Oromia Regional Health Bureau for permitting this study. We are also grateful to all the data collectors, supervisors, and respondents for this study.

\section{Funding}

This study was funded by Jimma University.

\section{Disclosure}

The authors report no conflicts of interest in this work.

\section{References}

1. Boxer J. The Handbook of Community Mental Health Nursing. In: Promoting Mental Health. 2005:149-163.

2. Stranges S, Samaraweera PC, Taggart F, Kandala NB, Stewart-Brown S. Major health-related behaviours and mental well-being in the general population: the health survey for England. BMJ Open. 2014;4(9): e005878-e005878. doi:10.1136/bmjopen-2014-005878

3. World Health Organization. Investing in Mental Health. 2003:3-49

4. Chisholm D, Heslin M, Docrat S, et al. Scaling-up services for psychosis, depression and epilepsy in sub-Saharan Africa and South Asia: development and application of a mental health systems planning tool (OneHealth). Epidemiol Psychiatr Sci. 2017;26(3):234-244. doi:10.1017/S2045796016000408

5. Caddick H, Horne B, Mackenzie J, Tilley H. Investing in Mental Health in Low-Income Countries. London: Overseas Development Institute; 2016:1-34.

6. Marquez PV, Saxena S. Making Mental Health a Global Priority. Cerebrum: Dana Foundation; 2016:1-14.

7. World Bank Group, World Health Organization. Out of the Shadows: Making Mental Health a Global Development Priority; 2016.

8. Rathod S, Pinninti N, Irfan M, et al. Mental Health Service Provision in Low- and Middle-Income Countries. Heal Serv Insights. 2017;10:1178632917694350.

9. Alloh FT, Regmi P, Onche I, Teijlingen E, Trenoweth S. Mental Health in low-and middle income countries (LMICs): going beyond the need for funding. Heal Prospect $J$ Public Heal. 2018;17(1):12-17. doi:10.3126/hprospect.v17i1.20351
10. Rojas G, Martínez V, Martínez P, Franco P, Jiménez-Molina Á. Improving mental health care in developing countries through digital technologies: a mini narrative review of the chilean case. Front Public Heal. 2019;7:1-9.

11. Weinmann S, Koesters M. Mental health service provision in low and middle-income countries: recent developments. Curr Opin Psychiatry. 2016;29(4):270-275. doi:10.1097/YCO.0000000000000256

12. Trautmann S, Rehm J, Wittchen H. The economic costs of mental disorders. EMBO Rep. 2016;17(9):1245-1249. doi:10.15252/ embr.201642951

13. Doran CM, Kinchin I. A review of the economic impact of mental illness. Aust Heal Rev. 2019;43(1):43. doi:10.1071/AH16115

14. Worle Health Organization. Integrating Mental Health into Primary Care. A Global Perspective. Worle Health Organization; 2009. Nervous and Mental Disease.

15. WHO: Department of mental health and substance Abuse. Ethiopia: mental Health Atlas; 2011. Available from: https://www.who.int/men tal_health/evidence/atlas/profiles/eth_mh_profile.pdf?ua $=1$. Accessed March 11, 2021.

16. Hunduma G, Girma M, Digaffe T, Weldegebreal F, Tola A. Prevalence and determinants of common mental illness among adult residents of Harari Regional State, Eastern Ethiopia. Pan Afr Med J. 2017;28(262):1-16. doi:10.11604/pamj.2017.28.262.12508

17. Bitew T. Prevalence and risk factors of depression in Ethiopia: a review. Ethiop J Health Sci. 2014;24(2):161-169. doi:10.4314/ejhs. v24i 2.9

18. Abdulahi H, Mariam DH, Kebede D. Burden of disease analysis in rural Ethiopia. Ethiop Med J. 2001;39(4):271-281.

19. Abbay AG, Mulatu AT, Azadi H. Community Knowledge, Perceived Beliefs and Associated Factors of Mental Distress: a Case Study from Northern Ethiopia. Int J Environ Res Public Heal. 2018;15:1-22.

20. Alem A, Kebede D, Fekadu A, et al. Clinical course and outcome of Schizophrenia in a predominantly treatment-naive cohort in rural ethiopia. Schizophr Bull. 2009;35(3):646-654. doi:10.1093/schbul/sbn029

21. Lund C, Breen A, Flisher AJ, et al. Poverty and common mental disorders in low and middle income countries: a systematic review. Soc Sci Med. 2010;71(3):517-528. doi:10.1016/j.socscimed.2010.04.027

22. Üçok A, Brohan E, Rose D, et al. Anticipated discrimination among people with schizophrenia. Acta Psychiatr Scand. 2012;125 (1):77-83. doi:10.1111/j.1600-0447.2011.01772.x

23. Ayano G, Assefa D. Experiences, Strengths and Challenges of Integration of Mental Health into Primary Care in Ethiopia. Experiences of East African Country. Fam Med Med Sci Res. 2016;5(3):3-6. doi:10.4172/2327-4972.1000204

24. Kakuma R, Minas H, van Ginneken N, et al. Human resources for mental health care: current situation and strategies for action. Lancet. 2011;378(9803):1654-1663. doi:10.1016/S0140-6736(11)61093-3

25. FMOH. National Mental Health Strategy 2012/13-2015/16. Fed Democr Repub Ethiop Minist Heal; 2013.

26. World Health Organization. Mental Health Atlas 2011; 2011. World Health Organization [Internet]. Available from: http://www.who.int/ mental_health/publications/mental_health_atlas_2011/en/. Accessed March 11, 2021.

27. World Health Organization. Mental Health Gap Action Programme Scaling Up Care for Mental, Neurological, and Substance Use Disorders. World Health Organization; 2008.

28. World Health Organization. Integrating Mental Health into Primary Care. A Global Perspective. World Health Organization; 2008.

29. Ministry of Health. 2nd Generation Health Extension Program; 2019.

30. Assefa Y, Gelaw YA, Hill PS, Taye BW, Van Damme W. Community health extension program of Ethiopia, 2003-2018: successes and challenges toward universal coverage for primary healthcare services. Global Health. 2019;15(1):1-11. doi:10.1186/s12992-019-0470-1

31. Sartorius N. Mental health and primary health care. Ment Health Fam Med. 2008;5(2):75-77. 
32. Ivbijaro G, Kolkiewicz L, Lionis C, Svab I, Cohen A, Sartorius N. Primary care mental health and Alma-Ata: from evidence to action. Ment Health Fam Med. 2008;5(2):67-69.

33. World Health Organization. Integrating Mental Health Services into Primary Health Care. Ment Heal Policy, Plan Serv Dev Inf Sheet; 2007. Sheet 3.

34. Mwape L, Sikwese A, Kapungwe A, et al. Integrating mental health into primary health care in Zambia: a care provider's perspective. Int J Ment Health Syst. 2010;4:4. doi:10.1186/1752-4458-4-21

35. Sudhakar M, Woldie M, Yitbarek K, Abamecha F, Tamirat A. Primary Care Systems Profiles and Performance (PRIMASYS): ethiopian Case study. Alliance Heal Policy Syst Res. 2017.

36. Wang H, Tesfaye R, Ramana G, Chekagn CT. Ethiopia Health Extension Program: An Institutionalized Community Approach for Universal Health Coverage. Ethiopia Health Extension Program: An Institutionalized Community Approach for Universal Health Coverage; 2016.

37. Federal Democratic Republic of Ethiopia Ministry of Health. Health Sector Transformation Plan. Addis Ababa, Ethiopia:Federal Democratic Republic of Ethiopia Ministry of Health;2015:1-116

38. Wakida EK, Okello ES, Rukundo GZ, et al. Health system constraints in integrating mental health services into primary healthcare in rural Uganda: perspectives of primary care providers. Int $J$ Ment Health Syst. 2019;13(1). doi:10.1186/s13033-019-0272-0

39. Arafat SMY, Roy S, Huq N. Integrating mental health into primary health care in Bangladesh: problems and prospects. Ment Heal Addict Res. 2018;3(2):1-2.

40. FMOH. Non-Communicable Diseases, Emergency Care and Mental Health. 2015:1-120

41. FMOH, HEPCAPS II Project. Health Extension Workers Time Motion Study Complemented by In-Depth Interviews Within Primary Health Care Units in Ethiopia; 2015.

42. Kassa GM, Abajobir AA. Prevalence of common mental illnesses in Ethiopia: a systematic review and meta-analysis. Neurol Psychiatry Brain Res. 2018;30(May):74-85. doi:10.1016/j.npbr.2018.06.001

43. Stein DJ, Seedat S, Herman A, et al. Lifetime prevalence of psychiatric disorders in South Africa. Br J Psychiatry. 2008;192(2):112-117. doi:10.1192/bjp.bp.106.029280

44. Tesfaye G, Derese A, Hambisa MT. Substance Use and Associated Factors among University Students in Ethiopia: a Cross-Sectional Study. J Addict. 2014;2014:1-8. doi:10.1155/2014/969837

45. Gebrie A, Alebel A, Zegeye A, Tesfaye B. Prevalence and predictors of khat chewing among Ethiopian university students: a systematic review and meta-analysis. PLoS One. 2018;13(4):1-15. doi:10.1371/ journal.pone.0195718

46. International Organisation for Migration. Ethiopia National Displacement Report; 2019

47. Egbe CO, Brooke-Sumner C, Kathree T, Selohilwe O, Thornicroft G, Petersen I. Psychiatric stigma and discrimination in South Africa: perspectives from key stakeholders. BMC Psychiatry. 2014;14 (1):1-14. doi:10.1186/1471-244X-14-191

48. Crabb J, Stewart RC, Kokota D, Masson N, Chabunya S, Krishnadas R. Attitudes towards mental illness in Malawi: a cross-sectional survey. BMC Public Health. 2012;12(1). doi:10.1186/1471-2458-12-541

\section{Risk Management and Healthcare Policy}

\section{Publish your work in this journal}

Risk Management and Healthcare Policy is an international, peerreviewed, open access journal focusing on all aspects of public health, policy, and preventative measures to promote good health and improve morbidity and mortality in the population. The journal welcomes submitted papers covering original research, basic science, clinical \& epidemiological studies, reviews and evaluations,
49. Maeseneer J, Forum E, Care P, et al. How Does Primary Health Care Respond To the Challenges of the Changing World? Br J Gen Pract. 2008;58(556):806-809. doi:10.3399/bjgp08X342697

50. Bresick G, Christians F, Makwero M, Besigye I, Malope S, Dullie L. Primary health care performance: a scoping review of the current state of measurement in Africa. BMJ Glob Heal. 2019;4(Suppl 8): e001496. doi:10.1136/bmjgh-2019-001496

51. Mash R, Howe A, Olayemi O, et al. Reflections on family medicine and primary healthcare in sub- Saharan Africa. BMJ Glob Heal. 2018;3:1-3.

52. Alem A, Jacobsson L, Hanlon C. Community-based mental health care in Africa: mental health workers' views. World Psychiatry. 2008;7(1):54-57. doi:10.1002/j.2051-5545.2008.tb00153.x

53. FDREMOH. National Mental Health Strategy 2012/13-2015/16. Federal Democratic Republic of Ethiopia Ministry of Health; 2011:1-114

54. Campos PA, Reich MR. Political Analysis for Health Policy Implementation. Heal Syst Reform. 2019;5(3):224-235. doi:10.10 80/23288604.2019.1625251

55. Mosquera PA, Hernández J, Vega R, et al. Challenges of implementing a primary health care strategy in a context of a market-oriented health care system: the experience of Bogota, Colombia. Int $J$ Health Plann Manage. 2014;29(4):e347-67. doi:10.1002/hpm.2228

56. Ayano G. Primary mental health care services in ethiopia: experiences, opportunities and challenges from East African Country. J Neuropsychopharmacol Ment Heal. 2016;1(4):1-3.

57. Wakida EK, Obua C, Rukundo GZ, Maling S, Talib ZM, Okello ES. Barriers and facilitators to the integration of mental health services into primary healthcare: a qualitative study among Ugandan primary care providers using the COM-B framework. BMC Health Serv Res. 2018;7:1-12.

58. Wakida EK, Talib ZM, Akena D, et al. Barriers and facilitators to the integration of mental health services into primary health care: a systematic review. Syst Rev. 2018;7(1):1-13. doi:10.1186/s13643018-0882-7

59. Federal Democratic, Republic of Ethiopia Ministry of Health. Ethiopia Health Accounts, 2013/14. Addis Ababa, Ethiopia:Federal Democratic, Republic of Ethiopia Ministry of Health; 2017.

60. Central Statistical Agency [Ethiopia] and ICF International. Ethiopia Demographic and Health Survey 2016. 2016:1-155

61. Yitbarek K, Abraham G, Morankar S. Contribution of women , $\mathrm{s}$ development army to maternal and child health in Ethiopia: a systematic review of evidence. BMJ Open. 2019;9:e025937. doi:10.1136/bmjopen-2018-025937

62. Han HR, Kim K, Murphy J, et al. Community health worker interventions to promote psychosocial outcomes among people living with HIV_A systematic review. PLoS One. 2018;13(4). doi:10.1371/journal.pone. 0194928

63. Barnett ML, Gonzalez A, Miranda J, Chavira DA, Lau AS. Mobilizing community health workers to address mental health disparities for underserved populations: a systematic review. Adm Policy Ment Heal Ment Heal Serv Res. 2018;45(2):195-211. doi:10.1007/ s10488-017-0815-0 is all easy to use. Visit http://www.dovepress.com/testimonials.php to read real quotes from published authors.

\section{Dovepress}

